\title{
NEONATAL FITS ASSOCIATED WITH HYPOMAGNESAEMIA
}

\author{
BY \\ J. A. DAVIS, D. R. HARVEY, and J. S. YU* \\ From the Nuffield Neonatal Research Unit, Institute of Child Health, Hammersmith Hospital, London W.12
}

(RECEIVED FOR PUBLICATION SEPTEMBER 21, 1964)

Kruse, Orent, and McCollum (1932) were the first to show conclusively that experimental magnesium deficiency in rats causes clinical symptoms. The magnesium deficiency syndrome in man has been reviewed by MacIntyre (1963). The cardinal feature of severe magnesium deficiency is fits; other symptoms and signs are muscular weakness, vertigo, mental changes, gross tremor, and alteration in the electroencephalographic pattern.

There are few reports of symptomatic magnesium deficiency in the paediatric literature and few data about normal serum magnesium levels (Gittleman, Pincus, Schmerzler, and Saito, 1956). The case reported here is, we believe, the first in which there are adequate data to support a diagnosis of hypomagnesaemic fits in the neonatal period.

\section{Case Report}

Clinical History. Infant Nigel B. was born on April 12, 1964 at 38 weeks' gestation and weighing $2,520 \mathrm{~g}$. at birth.

His mother was 23 years and this was her first pregnancy. Coeliac disease was diagnosed when she was 7 years old and she was treated with a starch-free diet in 1949. She had a dramatic gain in weight and returned to a normal diet in 1951; since then she has had intermittent steatorrhoeic diarrhoea but is often constipated. At the 29th week of pregnancy she developed a megaloblastic anaemia (haemoglobin $9.0 \mathrm{~g}$. $/ 100 \mathrm{ml}$.; serum folic acid $1.0 \mathrm{~m} \mu \mathrm{g} . / \mathrm{ml}$., and serum B12 $240 \mu \mu \mathrm{g} . / \mathrm{ml}$.) which was treated with folic acid and iron. Her haemoglobin rose to $13.0 \mathrm{~g} . / 100 \mathrm{ml}$. in mid-April.

She was fully investigated two weeks after delivery. Physical examination was normal except that she was small, being only $155 \mathrm{~cm}$. in height. A jejunal biopsy showed a flat mucosa, and barium follow-through demonstrated dilatation of the duodenum and jejunum with thickened primary folds. Serum calcium levels were $3 \cdot 9-4 \cdot 3 \mathrm{mEq}$, magnesium $1 \cdot 3-1 \cdot 4 \mathrm{mEq}$, and phosphate 1.6-1.7 mEq/l., and the phosphate excretion index was $+\mathbf{0} .088$ (normal). Folic acid absorption was low, $7 \%$ of a $50 \mu \mathrm{g}$. dose excreted in a 24-hour collection of urine. She is now on a gluten-free diet.

* Present address: Institute of Child Health, Royal Alexandra Hospital for Children, Sydney, N.S.W., Australia.
She was delivered by forceps, because of delay in the second stage of labour.

The baby was in good condition at birth and remained well until he was 8 days old. He was breast fed for five days but on the sixth day complementary feeds of evaporated cows' milk were introduced. From the 8th day he was fed entirely on evaporated cows' milk.

On the 8th day (April 19, 1964) generalized clonic convulsions began, this first episode of fits lasting 8 minutes. Physical examination showed no neck stiffness, fever, or tetany, but there were imposable tonic neck reflexes. The head circumference was $33.5 \mathrm{~cm}$. There was severe oral thrush.

Investigations. Haemcglobin $15 \cdot 1 \mathrm{~g} . / 100 \mathrm{ml}$. White cell count $17,000 /$ c.mm.; neutrophils, 7,650 ; lymphocytes, 7,480; eosinophils, 1,530; monocytes, 340; and platelets, $20,000 /$ c.mm.

Cerebrospinal fluid (obtained by cisternal puncture) was clear. There were 20 white cells/c.mm.; it was sterile on culture; glucose $55 \mathrm{mg} . / 100 \mathrm{ml}$; protein $85 \mathrm{mg} . / 100 \mathrm{ml}$. Blood sugar was $22.5 \mathrm{mg} . / 100 \mathrm{ml}$.; serum calcium, 2.6 $\mathrm{mEq} / \mathrm{l}$; ; and serum magnesium $0.9 \mathrm{mEq} / 1$.

Progress. Because of the equivocal cell count in the CSF, the baby was given a two-week course of the antibiotics (chloramphenicol, polymyxin, and cloxacillin). $\mathrm{He}$ was also given nystatin for the oral thrush. These were begun on the eighth day of life.

The fits continued throughout the next two days increasing in intensity and frequency, and they could not be adequately controlled by paraldehyde and chloral. On the tenth day, the baby had spasms of the limbs, as shown by episodic slow extension of his leg and dorsiflexion of his foot. Trousseau's sign was negative but Chvostek's sign was positive.

We have compressed the biochemical data into a chart (see Fig.). On the morning of the 11th day the baby was convulsing continuously and an EEG was taken while various substances, which might stop the convulsions, were injected intravenously. Pyridoxine $50 \mathrm{mg} ., 10 \mathrm{ml}$. $10 \%$ glucose, and $2 \mathrm{mEq}$ calcium as $10 \%$ calcium gluconate, were given at 10-minute intervals; there was no change in the clinical state nor in the EEG, though after the calcium injection the serum calcium had returned to normal levels. After half an hour's delay, $2.5 \mathrm{mEq}$ of 

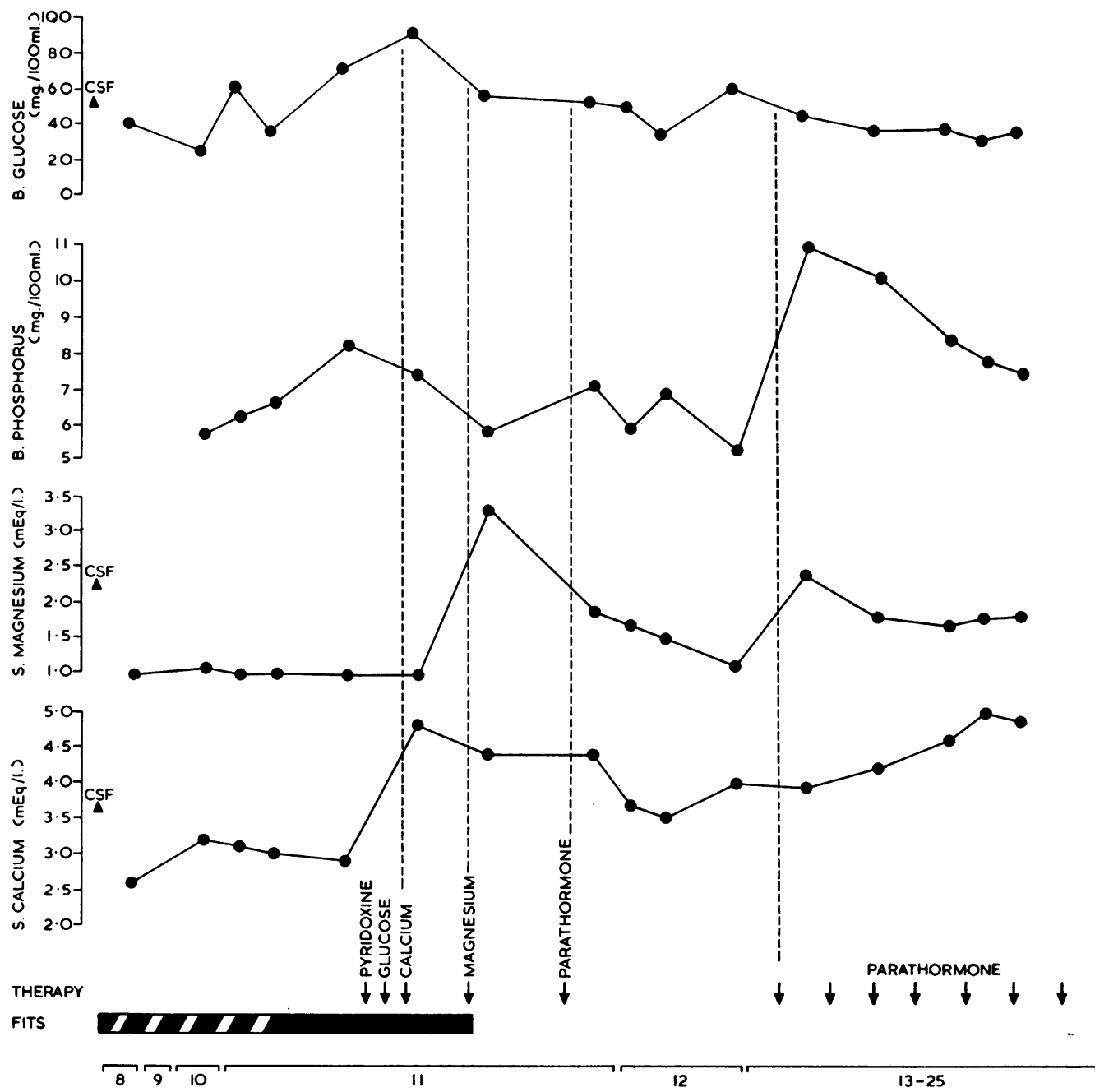

AGE (DAY OF LIFE)

FIG.-Showing biochemical data. The pied strip indicates intermittent fits and the rest indicates continuous fits.

magnesium were given intravenously and produced a dramatic response. The clonic convulsions ceased in $\mathbf{3 0}$ seconds and Chvostek's sign, which was strongly positive just after the injection, rapidly became negative. There was no immediate change in the EEG, but 2 days later it was nearly normal, and after 6 days it was entirely normal.

There were occasional bilateral myoclonic jerks involving the proximal limb muscles during the 24 hours following the magnesium injection, but no further convulsions.

Three clearances of calcium, magnesium, and phosphorus were estimated before and after treatment and these are shown in the Table. The second study, made after 15 USP units of parathyroid extract had been given, showed a marked reduction of calcium and magnesium excretion. On April 24 (at 13 days of age) the serum magnesium level had again fallen to $1 \cdot 1 \mathrm{mEq} / 1$. Since the evidence suggested a functional hypoparathyroidism, a course of parathyroid extract given by intramuscular injection was begun.

On the 13th day he had 7 USP units of parathyroid

TABLE

RESULTS OF THE CLEARANCE STUDIES (ml. $/ \mathrm{hr}$.)

\begin{tabular}{|c|c|c|c|}
\hline Clearance & $\begin{array}{c}\text { Before } \\
\text { Para- } \\
\text { thormone }\end{array}$ & $\begin{array}{l}\text { After Single } \\
\text { Dose of } 15 \\
\text { USP Units } \\
\text { of Para- } \\
\text { thormone }\end{array}$ & $\begin{array}{l}\text { When } \\
\text { Stabilized } \\
\text { on Para- } \\
\text { thormone }\end{array}$ \\
\hline $\begin{array}{l}\text { Phosphate (ml.) } \\
\text { Calcium (ml.) } \\
\text { Magnesium (ml.) }\end{array}$ & $\begin{array}{l}5 \cdot 6 \\
1.6 \\
5 \cdot 5\end{array}$ & $\begin{array}{l}7 \cdot 8 \\
0 \cdot 3 \\
0.4\end{array}$ & $\begin{array}{r}14 \cdot 7 \\
1.7 \\
1.8\end{array}$ \\
\hline
\end{tabular}


extract, on the next day 7 and 5 units, and thereafter 1 unit twice daily. His serum calcium and magnesium levels having returned to normal, treatment was stopped after 14 days of therapy. He was discharged on the 27th day and has since remained well, with no evidence of neurological damage.

Special Investigations. (1) Clearance Studies. Serum calcium and magnesium were determined by a flame spectrophotometric method (Alcock, MacIntyre, and Radde, 1960), phosphate by the Fisk and Subarrow method, using phosphomolybdic acid, and glucose by glucose-oxidase (Marks, 1959). Serum cortisol levels were determined fluorimetrically.

The clearance studies were all done during the same 12-hour period to minimize errors due to diurnal variation. The baby was given the same volume and strength of processed evaporated cows' milk.

Clearance figures have been used as one index of calcium, magnesium, and phosphate homeostasis: the lack of normal values for the neonatal period precludes the use of more complex expressions. Three serum levels were taken during each clearance study, and from these a mean clearance was derived. The results are shown in the Table.

At the time of the third clearance study the baby was clinically well, and the serum calcium and magnesium levels were 4.6 and $1.8 \mathrm{mEq} / 1$. respectively.

During the period when the infant was convulsing continuously, the plasma cortisol levels were 19-37 $\mu \mathrm{g}$./ $100 \mathrm{ml}$. Thirty minutes after the convulsions had stopped, the cortisol had fallen to $8 \mu \mathrm{g}$./100 ml., and it remained within this range for the rest of the study period.

(2) Electroencephalograms. Nine electrodes were used, the connexion being bipolar (scalp to scalp). Electrocardiogram and respiratory rate were recorded simultaneously.

(a) At the age of 8 days and 10 hours. The baby appeared clinically in the second stage of sleep for long periods, as judged by regular respiration $(45 / \mathrm{min}$.) and absence of eye movements, but the EEG did not show the episodic activity usually associated with this stage of sleep. Instead, it showed runs of unusually rhythmic activity usually at 4 to $7 \mathrm{c} / \mathrm{s}$. ( $40 \mu \mathrm{V}$ amplitude) appearing independently from either side of the head. On a few occasions there were short runs of slow activity $1.5 \mathrm{c} / \mathrm{s}$.) and once clear spike and wave activity at this frequency from both anterior leads. During the recording there were numerous episodes of single twitches of a limb or a digit, but there were no corresponding changes in the EEG. On the other hand, there were rather frequent instances of sharp waves on one or other side showing phase reversal about the midline. Very occasionally there was a bilaterally synchronous single sharp wave.

(b) At the age of 8 days and 15 hours. He was given $0.3 \mathrm{ml}$. paraldehyde $3 \frac{1}{2}$ hours before recording. Background activity was the same as in the previous record. One fit was observed. Clinically this consisted of an odd cry followed by twitching of the left leg preceding twitching of all limbs. During the fit there were only brief periods of apnoea. The EEG changes lasted about 50 seconds. At first there were alternate low amplitude spikes and high amplitude slow waves at $1.5 \mathrm{c} / \mathrm{s}$. from the right hemisphere only, but after a few seconds the left hemisphere was also involved. Almost continuous spike and wave activity continued, but the rate varied from 1 to $5 \mathrm{c} / \mathrm{s}$., the faster activity replacing the slow spike and wave in runs of a few seconds only. The spike and wave complex showed phase reversal about the midline on both sides. After the fit the record was flat for about half a minute.

(c) At the age of 10 days. Background activity was similar to that seen in previous records, but there were numerous instances of single monophasic sharp waves showing phase reversal about the midline on one or other side. Occasionally these sharp waves occurred in runs of a second or two, and occasionally there was a bilateral burst of irregular sharp and slow waves of about the same duration. During the recording there were no major fits, but frequent jerks of different parts of the body - single or repeated jerks lasting several seconds. However, there did not appear to be any association between these apparent focal fits and the sharp wave discharges on the EEG.

Following intravenous injections of $50 \mathrm{mg}$. pyridoxine, $10 \mathrm{ml} .10 \%$ glucose, and $2 \mathrm{mEq}$ calcium as $10 \%$ calcium gluconate, there was no change in the clinical state nor in the EEG record.

Immediately after intravenous injection of magnesium chloride $(2.5 \mathrm{mEq})$ the almost continuous jerking ceased. There was no immediate change in the EEG, and sharp waves from one or other hemisphere continued to appear. Gradually, however, the record became episodic, with bursts of higher amplitude activity of varying frequencies against a rather flat background about every 10 seconds. These bursts differed from normal episodic sleep activity only in that they contained moderate to high amplitude sharp waves on one or other or both sides.

(d) At the age of 12 days. The recording was made during varying stages of sleep. The earlier part of the record showed less rhythmic activity in the $\theta$ frequency range, was of higher amplitude, and contained more delta waves than previously seen. There were only a few sharp waves. The next section was very similar in background activity to the earliest records, and no sharp waves were seen. In the last section there was a return to the higher amplitude arrhythmic appearance with episodic sleep bursts containing sharp elements as in the last recording.

(e) At the age of 16 days. When the baby was awake the record was of low amplitude and arrhythmic containing elements at all frequencies. There were a few low amplitude sharp waves not showing phase reversal and of doubtful significance. During sleep rather indistinct episodic activity was seen.

(f) At the age of 97 days. An EEG recording was normal.

\section{Discussion}

Serum calcium and magnesium levels in infants of birth weight $1,500-2,500 \mathrm{~g}$. vary considerably during the first 48 hours, falling to a minimum level at 18-24 
hours before rising again. At 48 hours serum calcium is $4.4 \pm 0.3 \mathrm{SD} \mathrm{mEq} / \mathrm{l}$. (W. W. Payne, 1964, personal communication). Hypocalcaemia by adult standards is frequently seen in normal asymptomatic newborn infants.

Levels of serum calcium and magnesium in the neonatal period depend on the type of feed given. Breast-fed infants tend to have slightly higher calcium and magnesium levels at 5 days, while babies having processed cows' milk with added vitamin D have significantly lower calcium and magnesium levels at 5 days than on the first day of life (Gittleman, Pincus, and Schmerzler, 1964). Tufts and Greenberg (1938) showed that nursing rats with deficient magnesium diets have lower than normal quantities of magnesium in their milk and that their suckling young, even though their birth weight and initial serum magnesium may be normal, develop the magnesium deficiency syndrome at 2 to 3 weeks of age.

By the standards of this laboratory, the levels of both calcium and magnesium were low throughout the entire symptomatic period. The causes of these deficiencies may have been both pre- and postnatally determined. The blood glucose level remained within the normal range for a newborn infant of this weight.

At the time of the intravenous test doses of pyridoxine, glucose, calcium, and magnesium, the baby had been convulsing continuously for 4 hours and looked very ill. The tests were performed under continuous EEG control.

The one indisputable clinical fit that occurred during recording was accompanied by striking electroencephalographic abnormalities, showing sharp and slow wave complexes from the contralateral hemicranium, when the fit was lateralized, and then from leads on both sides. The interseizure records were not strikingly abnormal: the single focal sharp waves differed from those seen in recordings from normal newborn babies only in being more numerous and they did not coincide with single limb jerks. They did, however, disappear gradually following restoration of normal serum magnesium levels, and the other noticeable change was the appearance, for the first time following this treatment, of normal episodic sleep activity which had not accompanied the second stage of sleep in previous recordings (Harris and Tizard, 1960).

After the successive injections of pyridoxine, glucose, and calcium there was no improvement clinically or on the EEG tracing. Thirty minutes later $2.5 \mathrm{mEq}$ of magnesium were given, and within 30 seconds the convulsing ceased, not to recur, though the EEG changes persisted for 24 hours.
Whether the magnesium alone would have stopped the fits we cannot say, since it seems probable that calcium and magnesium are interrelated in their actions on the nervous system. Though it cannot be excluded, the dose of magnesium given was not thought to be sufficient to cause pharmacological CNS depression, and paraldehyde had had no effect.

In looking for a cause for the baby's hypomagnesaemia, it may be relevant that his mother had coeliac disease and suffers from intermittent diarrhoea on a normal diet. Booth, Babouris, Hanna, and MacIntyre (1963) described 42 cases of malabsorption of whom 15 had subnormal serum magnesium levels. After the dramatic response to magnesium in this baby, investigation of the mother showed a pathologically flattened jejunal biopsy with a low serum calcium $3 \cdot 9-4 \cdot 3 \mathrm{mEq} / 1$. and a serum magnesium of $1 \cdot 3-1 \cdot 5 \mathrm{mEq} / \mathrm{l}$. which is at the lower limits of the normal adult range (MacIntyre, 1963); a skeletal survey showed mild cortical thinning.

One can speculate that the mother's homeostatic mechanisms for magnesium conservation were under stress during her pregnancy, and that there was a compensatory increase in parathyroid activity. It also seems likely that her milk would be deficient in magnesium (Tufts and Greenberg, 1938). The lack of clinical evidence to support a diagnosis of hyperparathyroidism may be the result of an associated vitamin D deficiency which also occurs in malabsorption.

Impaired activity of the parathyroid glands has been suggested as a cause of the observed fall in serum calcium and magnesium in the first 48 hours of life in normal newborn infants (Smith, 1959). A high maternal parathormone level might depress the activity of the foetal parathyroid still further, and so delay the acquisition of normal function in the newborn infant.

In the absence of compensating parathyroid activity, the substitution of breast milk in the baby's diet by processed cows' milk, containing vitamin D, and an increased phosphate load, would tend to lower subsequent calcium and magnesium levels.

The clearance studies after a test dose of parathormone (15 USP units) suggest that the baby's own parathyroid gland had been unable to respond to low blood levels of calcium and magnesium by reducing urinary loss of these elements. When the plasma levels of magnesium and calcium were depressed to 0.9 and $2.6 \mathrm{mEq} / 1$., respectively, the infant was still excreting large quantities of magnesium and calcium in his urine. This is grossly abnormal. Parathyroid extract then caused a dramatic fall in the urinary excretion of calcium and magnesium. MacIntyre, Boss, and Troughton 
(1963) showed a similar response to pure parathormone in parathyroidectomized rats with magnesium deficiency, but were not able to demonstrate this response in normal rats.

The phosphate excretion did not increase significantly with parathyroid extract, a phenomenon recognized in newborn infants on the first day of life (Connelly, Crawford, and Watson, 1962).

After parathyroid extract had been administered for 6 days, in a dosage of 1 USP unit per day, the serum magnesium had risen to $1.8 \mathrm{mEq} / \mathrm{l}$. At this serum level the urinary clearance of magnesium was $1.8 \mathrm{ml}$. per hour, which is still less than the excretion at the time when the serum magnesium was only $0.9 \mathrm{mEq} / \mathrm{l}$. and before any parathyroid extract had been given.

These clearance studies, which closely parallel experimental findings in parathyroidectomized rats, strongly support the existence of a functional hypoparathyroidism during the initial illness of this infant.

\section{Summary}

The case of a newborn infant with persistent convulsions associated with low serum calcium and magnesium levels is described. Magnesium deficiency in the mother, as a result of coeliac disease, together with a diet of cows' milk containing vitamin $D$, are suggested as factors in the baby's hypomagnesaemia and hypocalcaemia.

Evidence is presented suggesting that the baby was deficient in parathormone and that a low serum magnesium level was a cardinal factor in the aetiology of the convulsions.

It is a pleasure to thank Professor J. P. M. Tizard for his EEG reports, Dr. I. MacIntyre for the calcium and magnesium estimations, and Dr. W. W. Payne for his advice and guidance.

Laboratory facilities were provided by the Sir William Coxen Trust.

\section{REFERENCES}

Alcock, N., MacIntyre, I., and Radde, I. (1960). The determination of magnesium in biological fluids and tissues by flame spectrophotometry. J. clin. Path., 13, 506.

Booth, C. C., Babouris, N., Hanna, S., and MacIntyre, I. (1963). Incidence of hypomagnesaemia in intestinal malabsorption. Brit. med. J., 2, 141.

Connelly, J. P., Crawford, J. D., and Watson, J. (1962). Studies of neonatal hyperphosphatemia. Pediatrics, 30, 425.

Gittleman, I. F., Pincus, J. B., and Schmerzler, E. (1964). Interrelationship of calcium and magnesium in the mature neonate. Amer. J. Dis. Child., 107, 119.

- _ _ - - and Saito, M. (1956). Hypocalcemia occurring on the first day of life in mature and premature infants. Pediatrics, $18,721$.

Harris, R., and Tizard, J. P. M. (1960). The electroencephalogram in neonatal convulsions. J. Pediat., 57, 501.

Kruse, H. D., Orent, E. R., and McCollum, E. V. (1932). Studies on magnesium deficiency in animals. Symptomatology resulting from magnesium deprivation. J. biol. Chem., 96, 519.

MacIntyre, I. (1963). Magnesium metabolism. Sci. Basis Med. Ann. Rev., 216.

- Boss, S., and Troughton, V. A. (1963). Parathyroid hormone and magnesium homeostasis. Nature (Lond.), 198, 1058.

Marks, V. (1959). An improved glucose-oxidase method for determining blood, c.s.f. and urine glucose levels. Clin. chim. Acta, 4, 395.

Smith, C. A. (1959). Physiology of the Newborn Infant, 3rd ed., p. 300. Blackwell, Oxford.

Tufts, E. V., and Greenberg, D. M. (1938). The biochemistry of magnesium deficiency. I. Chemical changes resulting from magnesium deprivation. J. biol. Chem., 122, 693. 